\title{
Correction: Immune profiling in diffuse large B-cell lymphoma and mantle cell lymphoma patients treated with autologous hematopoietic cell transplant
}

Megan M. Herr ${ }^{1}$ - Pallawi Torka ${ }^{1}$ Yali Zhang ${ }^{1} \cdot$ Paul K. Wallace $^{2} \cdot{\text { Joseph D. Tario } \text { Jr. }^{2} \cdot \text { Elizabeth A. Repasky }}^{3}$. George L. Chen ${ }^{1} \cdot$ Christine M. Ho ${ }^{1}$. Sophia R. Balderman ${ }^{1} \cdot$ Maureen Ross ${ }^{1} \cdot$ Bruno Paiva $^{4}$. Francisco J. Hernandez-llizaliturri ${ }^{1,3} \cdot$ Philip L. McCarthy ${ }^{1} \cdot$ Theresa Hahn $\mathbb{1}^{1}$

Published online: 30 August 2019

(c) The Author(s), under exclusive licence to Springer Nature Limited 2019

\section{Correction to: Bone Marrow Transplantation} https://doi.org/10.1038/s41409-019-0591-4
In the original Article, Fig. 1a had an erroneous annotation. This has been corrected in the HTML and PDF versions of this Article.

These authors contributed equally: Megan M. Herr, Pallawi Torka

The original article can be found online at https://doi.org/10.1038/ s41409-019-0591-4.

\section{Theresa Hahn}

Theresa.hahn@roswellpark.org

1 Department of Medicine, Roswell Park Comprehensive Cancer Center, Buffalo, NY, USA

2 Department of Flow \& Image Cytometry, Roswell Park Comprehensive Cancer Center, Buffalo, NY, USA

3 Department of Immunology, Roswell Park Comprehensive Cancer Center, Buffalo, NY, USA

4 Clínica Universidad de Navarra, Pamplona, Spain 